\title{
Reproduction and Lactation in the Rat on Highly Purified Diets
}

\author{
BY S. J. FOLLEY, K. M. HENRY aND S. K. KON \\ National Institute for Research in Dairying, University of Reading \\ (Received 3r Fanuary 1947)
}

During recent years much work has been carried out to determine what vitamins and other nutritional factors are necessary for successful reproduction and lactation in rats and mice. Earlier work in this field has been reviewed by Folley, Ikin, Kon \& Watson (1938) and by Foster, Jones, Dorfman \& Kobler (1943). Nakahara and his co-workers (Nakahara \& Inukai, I933; Nakahara, Inukai \& Kato, I934; Nakahara, Inukai, Kato \& Ugami, 1936) have described a diet on which rats would reproduce, but on which successful lactation could only be obtained by the addition of factors $L_{1}$ and $L_{2}$ which were present in liver and yeast respectively. Folley et al. (1938), using an apparently similar diet, failed to confirm these findings; they found that this basal diet was comparable with their stock diet as regards reproduction and lactation, and that consequently the addition of yeast or liver to the experimental diet had little or no effect.

Later Nakahara, Inukai \& Ugami (I939) pointed out that they had used a special type of baker's yeast deficient in factors $L_{1}$ and $L_{2}$ and suggested that the brewer's yeast used by Folley et al. (1938) had presumably contained both these factors.

Experiments have been in progress here for over five years in which reproduction and lactation have been studied with rats receiving a basal diet of purified foodstuffs and supplemented with the known vitamins alone or with various other additions. A preliminary report of some of these experiments has been published elsewhere (Folley, Henry \& Kon, 1942). A full account of the findings is given in the present communication.

\section{EXPERIMENTAL}

\section{(I) The diets}

The following diets were used in these experiments.

(a) The stock diet, diet 5 (Folley et al. 1938).

(b) A highly purified diet + solutions of pure vitamins, diet 155 . The dry diet had the following composition: sucrose 60, Glaxo A/E casein (flavin-free) 20, lard 3, ground-nut oil 12, salts (de Loureiro, I93I) 5. In addition, each animal received daily, separately from the diet, vitamin $B_{1}$ I $5 \mu \mathrm{g}$., riboflavin $50 \mu \mathrm{g}$., vitamin $\mathrm{B}_{6}$ I0 $\mu \mathrm{g}$., calcium pantothenate $300 \mu \mathrm{g}$., choline hydrochloride $3 \mathrm{mg}$., nicotinic acid $\mathrm{I} \mathrm{mg}$., inositol $\mathrm{I} \mathrm{mg}$., $p$-aminobenzoic acid $3 \mathrm{mg}$., 2-methyl- $\mathrm{:4-diacetyl}$ naphthohydroquinone (vitamin $\mathrm{K}$ ) $100 \mu \mathrm{g}$. dissolved in $40 \mathrm{mg}$. cod-liver oil; $2 \mathrm{mg}$. $\alpha$-tocopheryl acetate (vitamin $E$ ) dissolved in arachis oil was given once a week. No vitamin $\mathrm{K}$ and cod-liver oil were given on the day when vitamin $\mathrm{E}$ was fed, since Mackenzie, Mackenzie \& McCollum (1941) noted that vitamin E-deficiency symptoms developed in rats when vitamin E and cod-liver oil were fed together, and attributed this finding to the destruction of vitamin $E$ by the cod-liver oil. 
During pregnancy the daily intake of riboflavin, nicotinic acid, inositol and choline was doubled and that of vitamins $B_{1}$ and $B_{6}$ trebled; the two latter were further increased to I 20 and $50 \mu \mathrm{g}$. respectively during lactation.

(c) Diet 187 was the same as diet 155 with $0.2 \%$ cystine added to the dry basal diet. This was done after the publication of an article by Sure (1941), in which he claimed that successful lactation could only be obtained with a diet similar to diet 155 if $0.2 \%$ cystine was added during lactation.

(d) Towards the end of the investigation diet $27 \mathrm{I}$ was used. It was the same as diet 155 with the addition of $0.4 \%$ of each of the amino-acids, cystine, arginine and histidine. Nelson $\&$ Evans (1945) found that the growth and survival of rats on synthetic diets supplemented with pure vitamins could be improved by increasing the extracted casein in the diet from 24 to $27 \%$; they suggested that the improvement might be due, in part, to an increase in the amino-acid intake. After consultation with $\mathrm{Dr} \mathrm{W}$. E. Gaunt it was decided that the three amino-acids listed above should be added to the diet. Biotin and folic acid were, by this time, available in pure form. In diet $27 \mathrm{I}$, therefore, I $\mu \mathrm{g}$. biotin and $10 \mu \mathrm{g}$. folic acid were given daily in addition to the other vitamins included in diet 155 , these quantities being doubled during pregnancy and lactation.

\section{(2) Procedure}

In all the experiments the foundation stock consisted of black-and-white females weaned from the stock diet when they were 2 I days old. Litter-mates were placed on each diet under investigation. Following the usual practice of this laboratory regular vaginal smears of all animals were taken from the time that they were about 3 months old. All animals were mated with stock colony bucks. Litters were reduced to eight when young were born in excess of this number, females being kept for preference. Litters of females receiving the stock diet were weaned when 2 I days old. With the purified diets it was found necessary to prolong the period of lactation until the young were strong enough to fend for themselves. Except where otherwise stated, the mothers were killed when they had either reared one litter or twice failed to do so.

In some experiments a number of males was kept and their growth rate studied for periods of 4 to 27 or 28 weeks after weaning, the fertility of some of them being proved by positive mating with stock-colony females. The growth rates of the females were also recorded.

\section{(3) Organ weights}

On autopsy of some of the rats it was noticed that the thyroids of male rats receiving the purified diets were definitely smaller than those of normal animals. It was therefore decided to take the following organs from females at autopsy: pituitary, thyroids, adrenals, ovaries and, in later experiments only, the uterus. With males the pituitary, thyroids, adrenals, testes, prostate and seminal vesicles were taken. These organs were weighed fresh immediately after dissection. For purposes of comparison one group of females maintained on the stock diet was autopsied. Groups of control males were also killed at different ages.

\section{(4) Experiment I. Reproduction, lactation and growth on highly purified diets}

The foundation stock in this experiment consisted of eight pairs of litter-mates which were given either the stock diet or diet ${ }^{5} 55$. The results of this experiment are shown in Tables I (reproduction and lactation), 2 (growth) and 7 (weight of organs for males). Table $\mathbf{I}$, which is self-explanatory, includes the extra control group which was added because organs were not taken from the foundation stock animals.

Certain apparent discrepancies in this table need explanation. Of six females in the control group four reared their first litter, one twice failed to rear a litter, while the remaining animal, having failed to rear one litter, could not be mated a second time owing to an abnormal oestrous cycle. One foundation-stock female on diet I $_{55}$, 


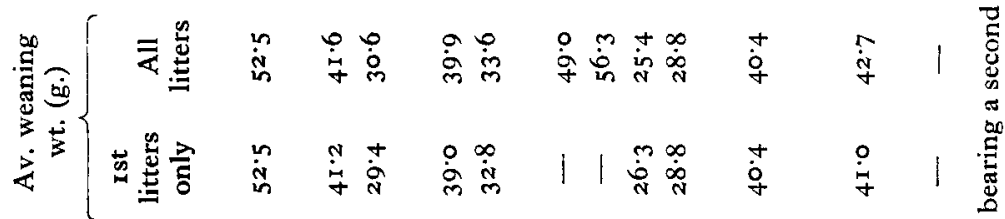

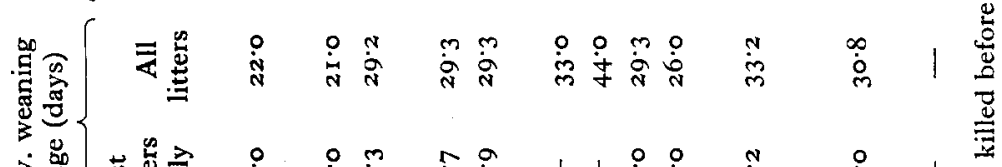

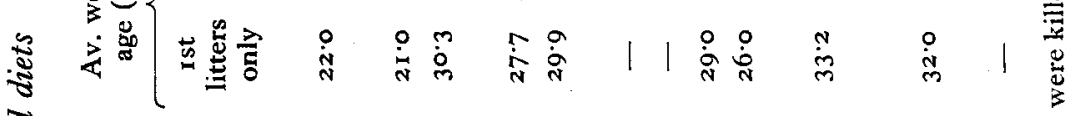

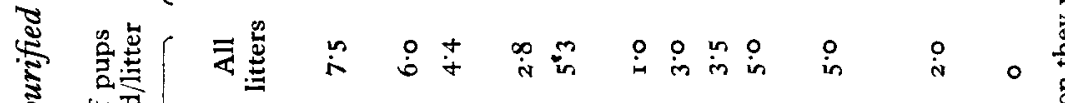

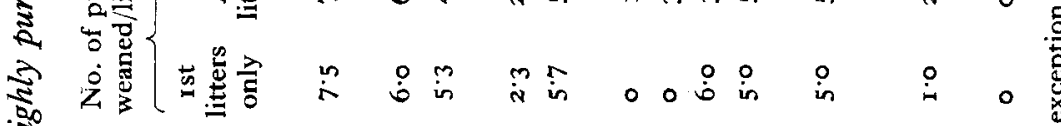

₹

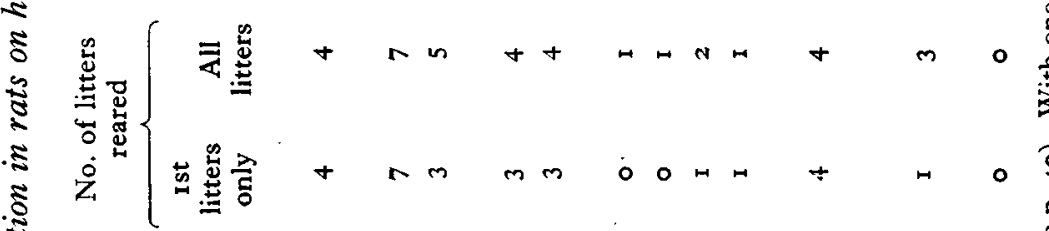

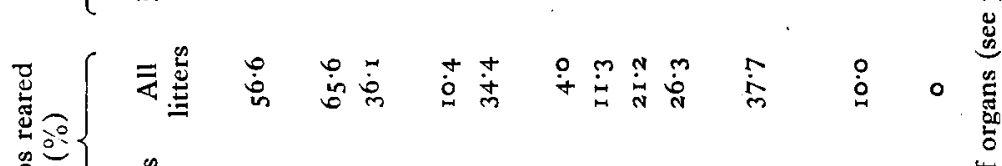

売

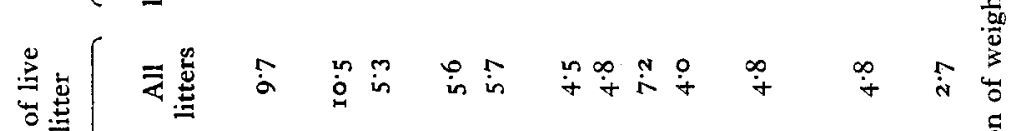

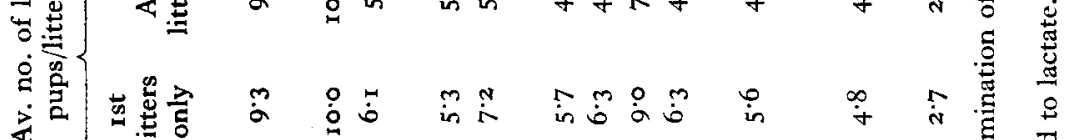

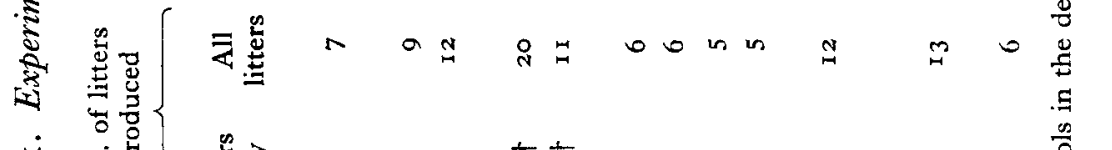

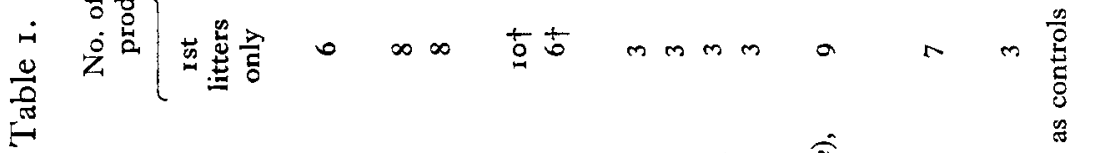

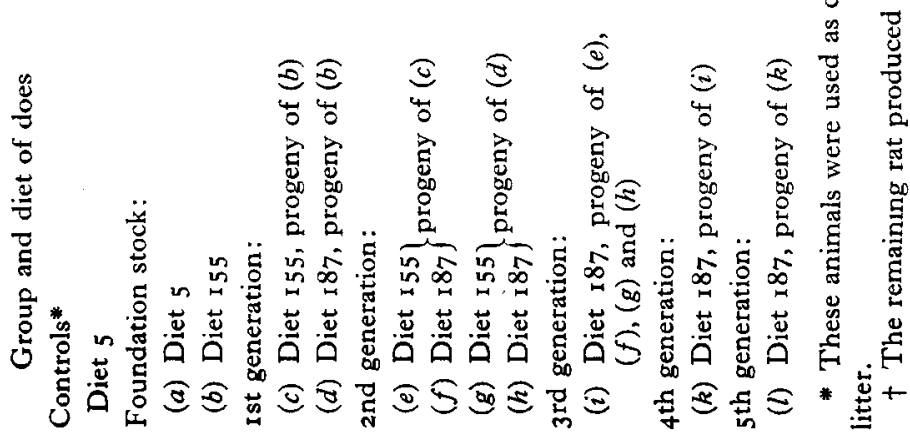




\begin{tabular}{|c|c|c|c|c|c|c|c|c|}
\hline 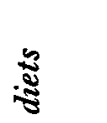 & 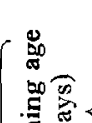 & $\int$ & 1 & 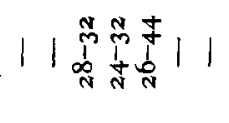 & 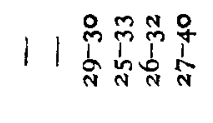 & 11 旡声总 & 1111 & 111 \\
\hline 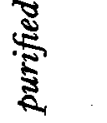 & $\sum^{50}$ & 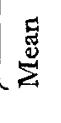 & $\vec{N}$ & || 䓞芯总| & 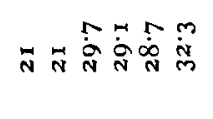 & 11 in & 1111 & 111 \\
\hline 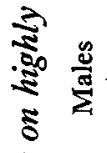 & 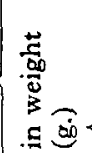 & $\int$ & $\begin{array}{l}0 \\
0 \\
0 \\
0 \\
0\end{array}$ & 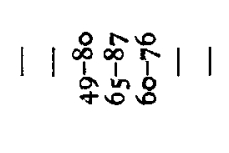 & 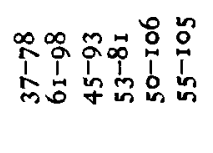 & 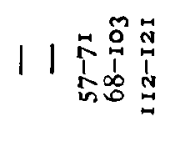 & 1111 & 111 \\
\hline ક & ชू. & 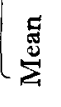 & : & || $\begin{array}{l}0 \\
\infty \\
0\end{array}$ & 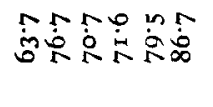 & 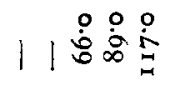 & 1111 & 111 \\
\hline & $\dot{z}$ & 量 & $\stackrel{4}{+}$ & $|1 \ln 0+| 1$ & 009000 & $11+m m$ & 1111 & 111 \\
\hline
\end{tabular}

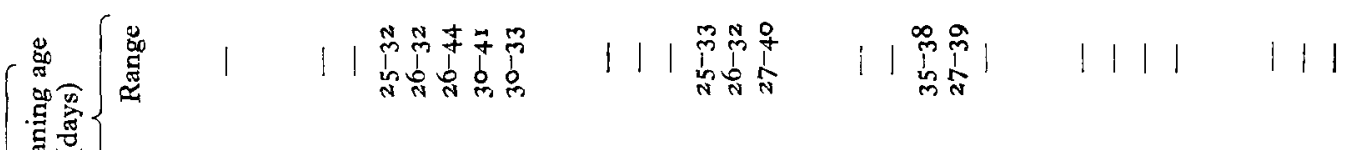

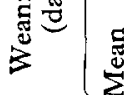

ล

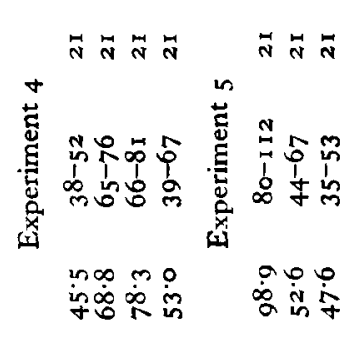

这

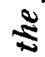

$\underset{\mathscr{L}}{\stackrel{5}{5}}$
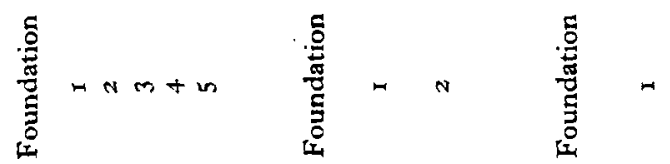

تٕ

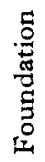

:

.

ป

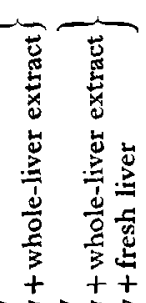

$\bar{\Delta}$ 
having failed on several occasions to become pregnant, finally gave birth to a small litter which she failed to rear. Twelve females whose mothers had received diet 155 formed the Ist generation, and all received diet 155 from weaning and were eventually mated. Ten of these animals had given birth to litters by the time the article by Sure (194I) was noticed in which he recommended the inclusion of cystine in purified diets in order to obtain successful lactation. The two animals which had not already produced litters, together with four animals which had already had one litter, subsequently received diet 187 during the last week of pregnancy and the lactation period. As a result, in Table $\mathrm{I}$, column $\mathrm{I}$, four animals in the first generation appear in line $(c)$ as well as in line $(d)$. Subsequent to this division most animals in both groups had two pregnancies before they were killed, one animal died of pneumonia before the final mating, and two others failed to become pregnant in spite of repeated matings. Two females in the third generation died after giving birth to their first litter, one of them from pneumonia.

Tables I and 2 show that growth, reproduction and lactation were all subnormal on diet 155 . The addition of $0.2 \%$ cystine to the diet seemed to cause some improvement in the lactational performance, and for the last three generations this diet was fed during the last week of pregnancy and during lactation. With succeeding generations there was a decrease both in the number of young born and in the percentage reared.

Some difficulty was experienced in mating females of the fourth and fifth generation owing to irregularities in the oestrous cycle; true oestrus only lasted for a few hours instead of the normal $24 \mathrm{hr}$.

A few animals became noticeably grey on the neck and shoulders after they had been on diet ${ }_{55}$ for 6-8 weeks. This condition, however, cleared up spontaneously in the course of the next 3 or 4 weeks.

\section{(5) Experiment 2. The effect on growth, reproduction and lactation, of the addition of milk to a highly purified diet}

This experiment was started after the first generation of the experiment described above had been weaned. Since it was evident that growth, reproduction and lactation on diet 155 were subnormal in comparison with the performance of stock-colony animals, the effect of the addition of small amounts of milk to diet I 55 was studied.

Six pairs of litter-mate does from the stock colony received at weaning diet 155 alone or with the addition of $5 \mathrm{ml}$. liquid whole milk daily. Twelve young of the mothers receiving milk also received $5 \mathrm{ml}$. milk daily in addition to diet ${ }_{55}$ until they were 4 weeks old. These animals were then divided into two groups, litter-mates being given 5 or to $\mathrm{ml}$. milk daily. The results of this experiment are given in Tables 2, 3 and 7 . One animal receiving $10 \mathrm{ml}$. milk died 6 weeks after it had been weaned. Another animal had to be killed after the birth of its first litter owing to prolapse of the uterus.

The addition of $5 \mathrm{ml}$. milk to diet 155 caused some improvement in the growth rate; this was more noticeable with males than with females (Table 2); doubling the milk intake caused only very slight further improvement with males and none with 


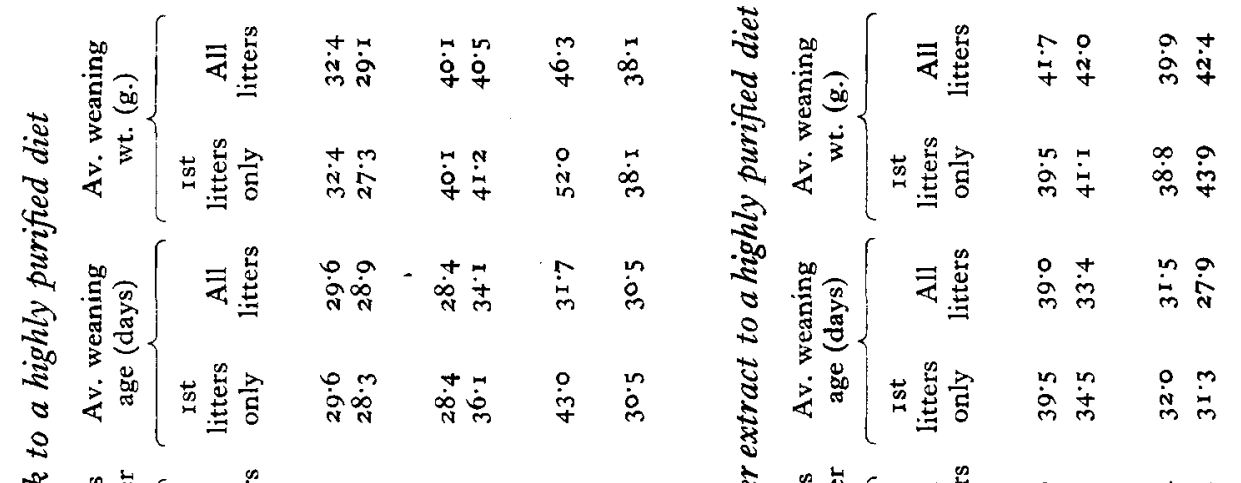

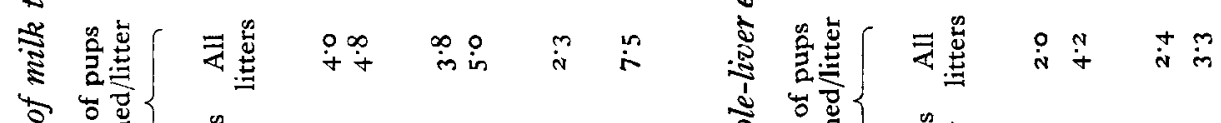

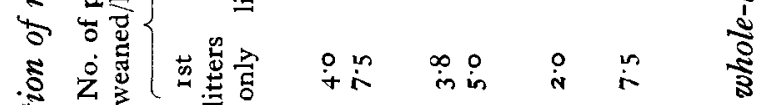

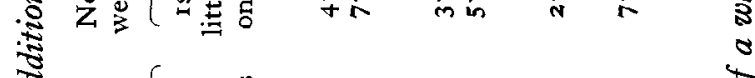
s 放

ริำ 童 s

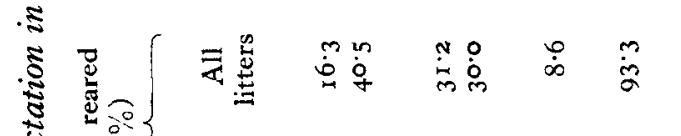

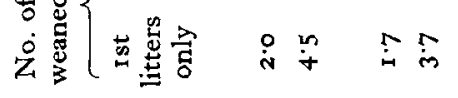

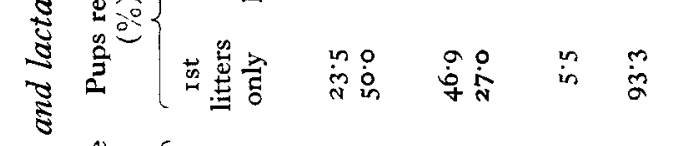

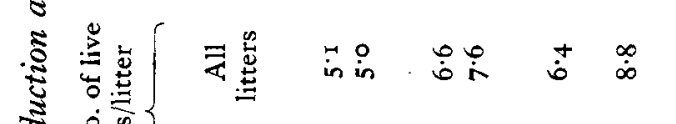

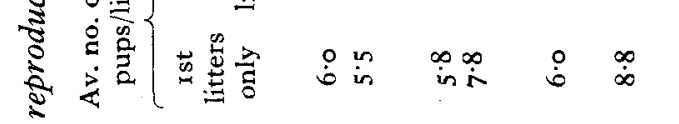

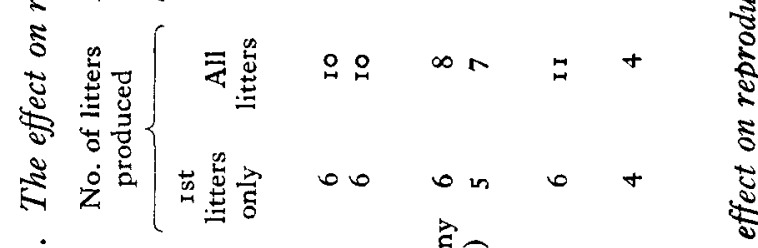

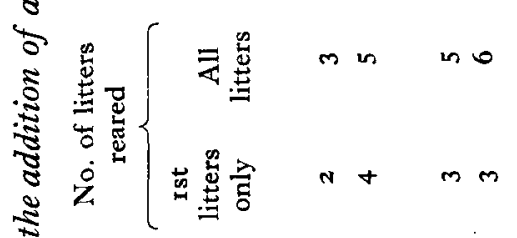

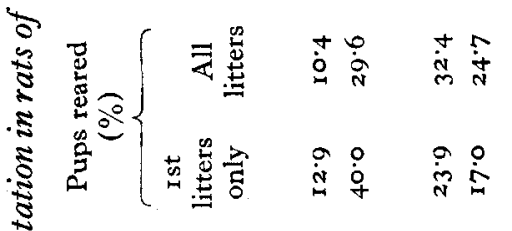

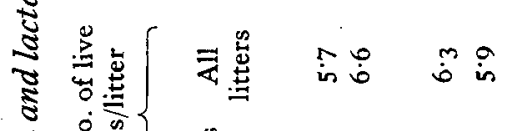

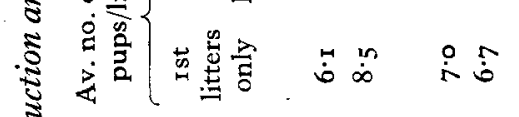

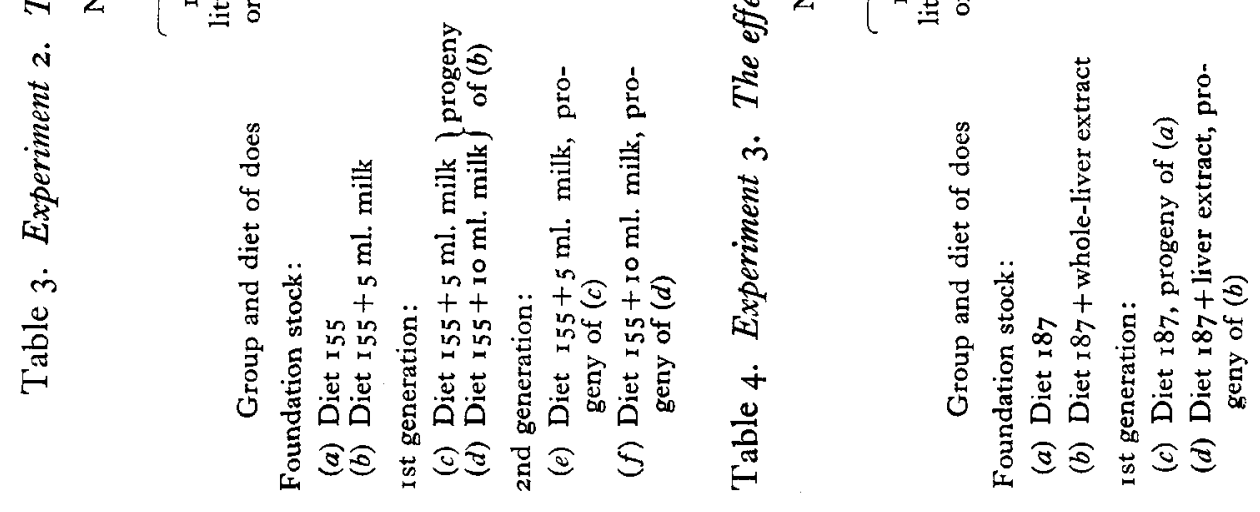


females. The milk supplement had no effect on the number or size of the litter born, but a higher percentage of young was reared. The results obtained when the daily milk allowance was doubled are inconclusive, but, as explained above, few animals were available, particularly of those receiving $10 \mathrm{ml}$. milk. This experiment was not continued for a third generation, since the milk did not exert a spectacular effect and only two females were available in the group receiving $5 \mathrm{ml}$. milk.

(6) Experiment 3. The effect on growth, reproduction and lactation of the addition of a whole-liver extract to a highly purified diet

The two experiments described above showed that it is possible to maintain reproduction and lactation for five generations using a highly purified diet, and that the addition of milk to the diet caused only slight improvement in growth and lactation. In view of these results it was decided to see whether or not the addition of a wholeliver extract would have a more beneficial effect. Since the addition of cystine appeared to cause some improvement in lactational performance, diet 187 was used in this and subsequent experiments.

Six pairs of females received, from weaning, diet 187 alone or with the daily addition of a concentrate prepared from an aqueous acetone extract of whole liver and equivalent to $3 \mathrm{~g}$. fresh liver. During pregnancy and lactation the dose of the liver extract was doubled. In this experiment all animals had two pregnancies before they were killed.

The results of this experiment are shown in Tables 2 and 4 . Only three females were available for the first generation on diet 187 alone. In this generation one female in the liver-extract group died after the birth of her first litter. The performance of the foundation stock in this experiment indicated that some improvement in growth, reproduction and lactation was effected by the inclusion of the whole-liver extract in the diet, but the improvement in reproduction and lactation was not maintained in the first generation. This conclusion is uncertain, however, since the group of animals receiving diet 187 alone was very small. The experiment was concluded with the weaning of the second generation, since the results showed that a whole-liver extract did not supply all the additional factors necessary for successful lactation.

Ten males of the first generation were divided into three groups and given diet 187 alone, with the addition of the whole-liver extract, or of $\mathbf{2} \mathrm{g}$. fresh liver daily. The addition of fresh liver caused a marked improvement in the growth rate, which was now comparable with that of stock-colony animals. It may be concluded from this that fresh liver supplied factors necessary for normal growth, but that these were only partially transferred to a whole-liver extract.

(7) Experiment 4. The effect on growth, reproduction and lactation of the addition of a whole-liver extract, of fresh liver or of a biotin concentrate to a highly purified diet

The results of Exp. 3 showed that a whole-liver extract caused some improvement in growth, reproduction and lactation in comparison with diet 187 alone, and that the addition of fresh liver caused normal growth in young male rats. It was decided, 
therefore, to repeat Exp. 3 and to include a group of rats receiving diet 187 supplemented with fresh liver. By this time a biotin concentrate was available in this country, and an additional group of animals receiving diet 187 supplemented with biotin was included. Six litters of four female rats were used, and litter-mates were placed on each of the following diets: (I) diet 187 ; (2) diet $187+\mathrm{I} \mathrm{ml}$. whole-liver extract equivalent to $3 \mathrm{~g}$. fresh liver daily; (3) diet $187+\mathrm{I} \cdot 5 \mathrm{~g}$. fresh liver daily; (4) diet $\mathrm{I} 87+\mathrm{I} \mu \mathrm{g}$. biotin daily, given as a concentrate. During pregnancy and lactation these daily supplements were doubled. The does were killed after their second pregnancy. In this and the following experiment it was considered more profitable to try to obtain normal reproduction and lactation in the foundation stock before determining the effects in succeeding generations, and the performance of the first generation was not studied.

The results of this experiment are shown in Tables 2 and 5. It will be seen that the addition of the whole-liver extract and of the fresh liver caused an improvement in growth rate and in lactational performance. This was more marked with fresh liver where growth, reproduction and lactation compared favourably with those of rats from the same colony receiving the stock-colony diet (diet 5). The addition of the biotin concentrate caused some improvement in the growth rate, the lactational performance of this group being intermediate between that of the liver-extract and freshliver groups.

(8) Experiment 5. The effect on growth, reproduction and lactation of the addition of certain amino-acids, biotin and folic acid to a highly purified diet

It was found in Exp. 4 that reproduction and lactation on diet 187 could be improved by the addition of $\mathrm{x} \mu \mathrm{g}$. biotin daily, given as a concentrate. Folic acid concentrates have been shown to improve lactation in mice (Cerecedo \& Vinson, 1944a) and in rats (Cerecedo \& Vinson, 1944b). As already mentioned on p. 40 it had been suggested that the addition of extra amounts of arginine, histidine and cystine to diet 187 might prove advantageous. A further experiment was carried out, therefore, in which a comparison was made between diets 5,187 and 271 . Eight litters of three female rats were used, litter-mates being placed on each of the three diets to be studied. The results of this experiment are given in Tables 2 and 6 . Table 2 shows that the addition of folic acid, biotin, arginine, histidine and cystine to the synthetic diet caused no improvement in the growth rate of the recipients over that of animals receiving diet 187 , and the growth in both these groups was inferior to that observed in the rats receiving the stock-colony diet. At the same time, these additions had little or no effect on the reproductive and lactational performance of the rats. There was some indication of an improvement in the numbers of young born and weaned when the first litters only were considered, but this was not maintained with the second litters. It may be noted that the weaning weights of the young rats whose mothers received diets 187 and $27 \mathrm{I}$ were rather lower than those observed previously with purified diets, in spite of the prolonged period of lactation. 
Vol. I
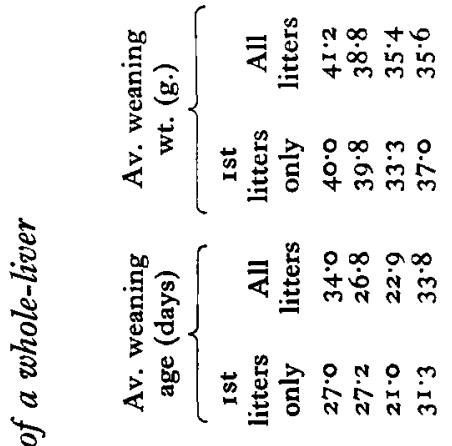

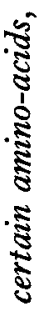

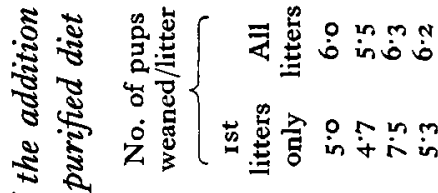

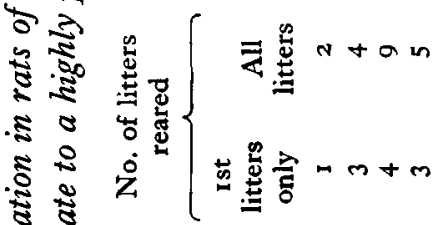

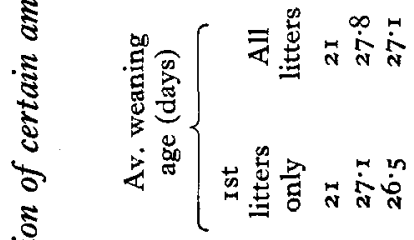

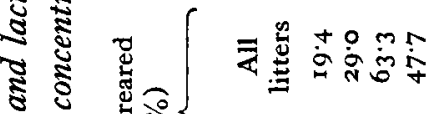

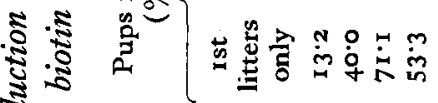

胥

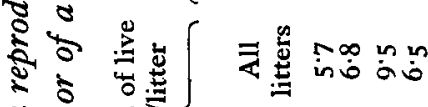

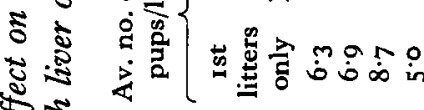

赵事

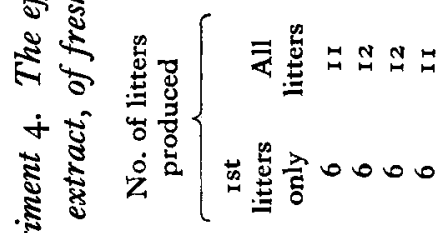

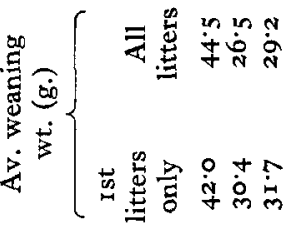

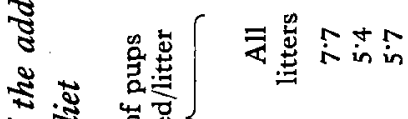

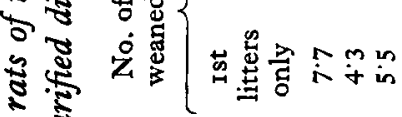

ह

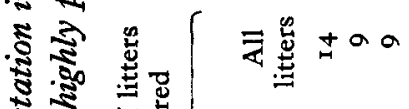

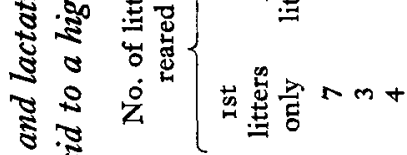

离

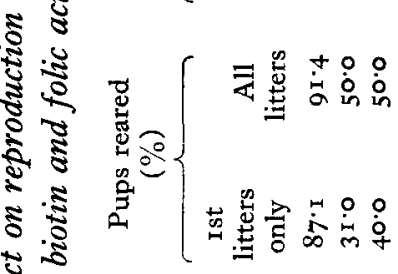

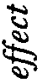

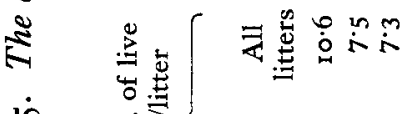

的宫离

官

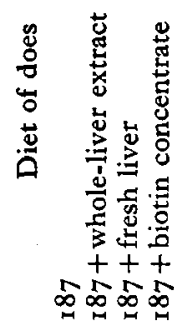

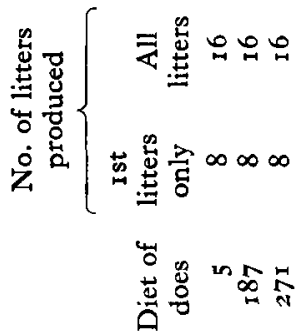




\section{(9) The weights of the reproductive organs and endocrine glands}

Males. The mean organ weights for all groups are given in Table 7. Groups of controls killed at comparable ages were available for comparison with all the experimental groups.

In all groups the thyroids were noticeably lighter, both absolutely and relatively, than those of controls. This would appear to indicate that in male rats reared on diets 155 and 187 , even when supplemented with milk, the thyrotrophic activity of the pituitary is diminished. It is puzzling that this observation was only made with males. No significant differences between rats on control and experimental diets were observed in the mean weights of the pituitary and adrenals.

The changes observed in the mean weights of the testes, prostate and seminal vesicles must be interpreted in the light of the fact (see Table 7) that on the relative basis, the testes of rats maintained on the stock diet underwent a progressive decrease in weight over the period studied (60-2I 7 days). Even on an absolute basis the testes of the oldest rats (217 days) were lighter than those of any of the other three control groups. Consideration of the variations in the weights of the prostate and seminal vesicles of the controls indicates that the androgenic potency of the testes reaches a peak which cannot be located from the limited data available but which certainly falls within the period studied. It is clear that at an age of 217 days the endocrine activity of the testes has undergone a marked decline.

These considerations permit a reasonable interpretation of the data for the animals on the experimental diets. It will be seen that the testes of the experimental rats killed at 99 and 135 days were lighter (absolute basis) than those of the corresponding controls. Of the six groups killed at 217 days, however, this was true for only three. When the correction for body weight is applied, the situation is reversed in all but the group receiving diet $\mathrm{I} 55$ and killed at 99 days. For the groups killed at 99 and $133^{-}$ 135 days, the prostate and seminal vesicles were, on the whole, heavier in the control rats than in those receiving diets 155 or 187 . For rats killed at 187 days, however, the advantage lay with the experimental groups. From consideration of the values for control rats killed at various ages, it seems reasonable to conclude that, in the animals maintained on the experimental diets, the functional development of the testes was retarded as compared with that of the controls.

Females. For all groups the mean weights of the endocrine glands and reproductive organs were less than the mean values for a group of control females maintained on the stock diet and killed at an average age of 191 days after they had had one or two litters. When the values were calculated to a roo g. body-weight basis (relative values), the differences between the values for the control group and the groups receiving diets 155 and 187 were no longer significant. To save space, these figures have been omitted from Table 7 .

Despite the fact that in the females, unlike the males, the experimental diets had no effect on the weights of the thyroids it seemed possible that the inferior lactational performance of the does receiving diet 187 might be partly due to hypothyroidism not associated with marked changes in thyroid weight. Accordingly three experiments 


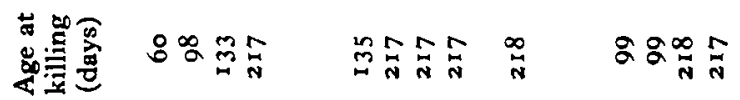

ฐับ

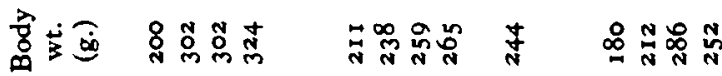

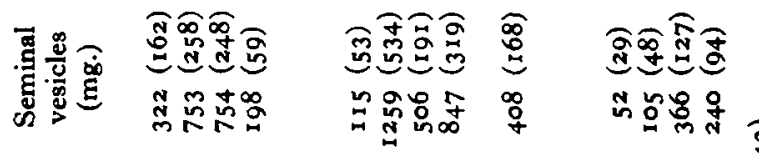

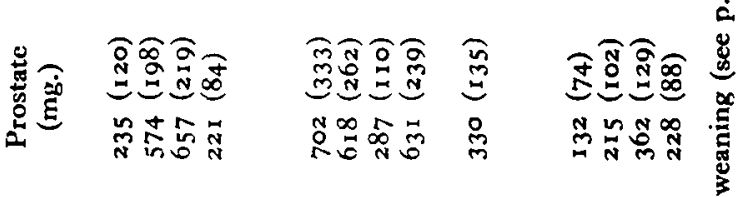

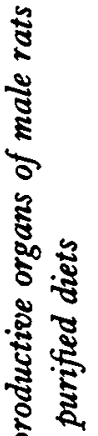

(a)

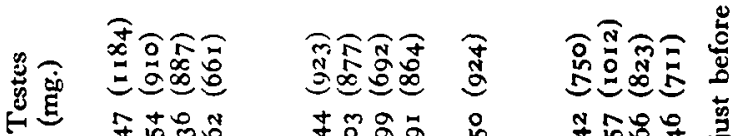

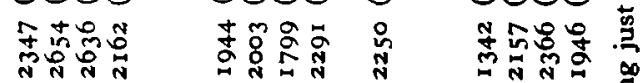

- 8 कात

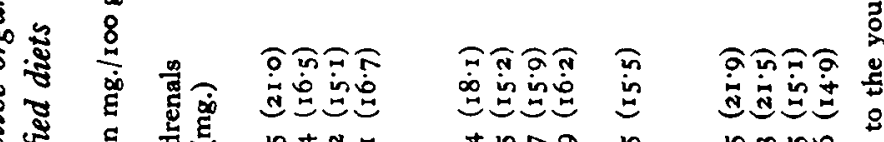

क्ष

है

है

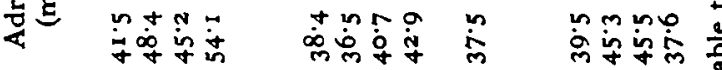

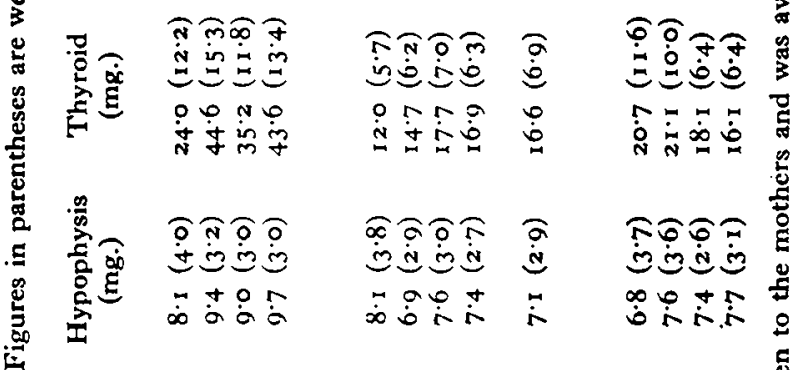

$\stackrel{2}{2}$

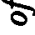

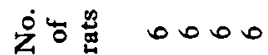

$\underbrace{N}+n+$

on mo

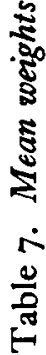

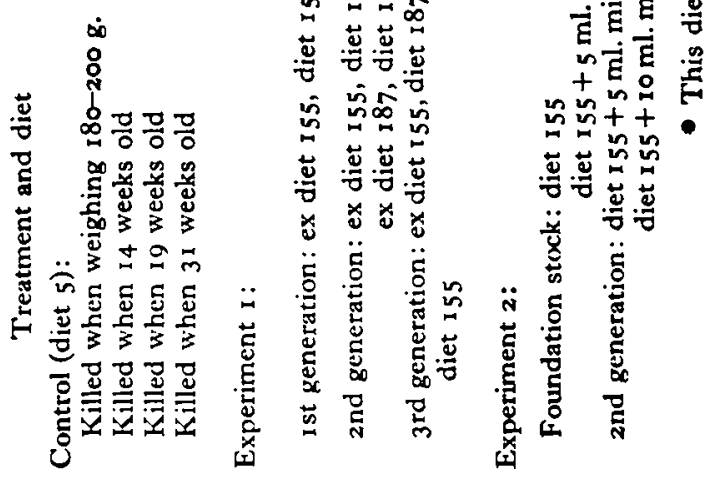


were carried out in which compressed cholesterol tablets containing 5 or $10 \mathrm{mg}$. disodium thyroxine were implanted subcutaneously in newly weaned female rats. 'The results were completely negative and details have not been reported in order to save space.

\section{DISCUSSION}

The experiments described above show that it is possible to rear five generations of rats on a highly purified diet to which known vitamins and other factors are added. With similar diets Jukes (1940) reported the rearing of two generations, while Henderson, McIntire, Waisman \& Elvehjem (1942) and Vinson \& Cerecedo (1943) successfully reared four generations. Working with mice Rogers, McElroy \& Cowgill (1942) and Foster et al. (1943) reared two and three generations respectively.

Growth, reproduction and lactation were subnormal on our purified diet, but some improvement in one or more of these respects was obtained by the addition of small amounts of milk, of a whole-liver extract or of a biotin concentrate. The addition of fresh liver resulted in almost normal performance. Various reports have appeared in the literature in which growth alone or together with reproduction and lactation has been studied with diets very similar to those used in the present work. In many experiments the added vitamins were incorporated in the diet so that the exact intake of these factors is difficult to assess. Thus Voris, Black, Swift \& French (1942) obtained growth in rats comparable with that of their stock-colony animals, but their supplements were probably higher than those in the present work, and the addition of $0.2 \%$ liver extract was without effect. Miller \& Baumann (1944) observed subnormal growth when the more readily available vitamins were given, but when these were replaced, at a lower level, by a brewer's yeast extract, normal growth was obtained. They concluded that yeast contained an unidentified but essential growth factor. Richardson, Hogan, Long \& Itschner (194I) also obtained normal growth in rats using supplements comparable with those of Voris et al. (1942). Richardson, Long \& Hogan (1942), however, found that on this diet only $25 \%$ success in lactation was obtained, but if $4 \%$ of a liver extract was added, $75 \%$ of young of normal size were reared. Foster $\mathrm{et} \mathrm{al}$. (1943), using a similar diet, found that mice successfully reared $6 \mathrm{r} \%$ of their young as compared with $85 \%$ reared by stock animals, the addition of $2 \%$ liver extract to the experimental diet being without effect. Ershoff (1943), also using this type of diet for rats, observed normal growth and reproduction but lactational failure. Very recently Rombouts \& Querido (1946) reported slightly subnormal growth in male rats on a similar diet, and observed only $35 \%$ success in lactation with females although they considered reproduction satisfactory. Cox \& Imboden (1936a) concluded that satisfactory reproduction and lactation could be obtained with synthetic diets provided that sufficient amounts of the B vitamins were added. For this purpose they used an aqueous extract of brewer's yeast.

It will be noted that in the first experiment described here the total number of pups reared decreased with succeeding generations. In this connexion it is of interest that Foster et al. (1943) and Cox \& Imboden (1936b) observed some falling off in the 
lactational performance of second and third generation females on a purified diet. The latter authors were inclined to attribute this to a seasonal variation.

Hartman \& Cary (1942), using a synthetic diet which contained some yeast and was ، supplemented with pure vitamins, obtained a $90 \%$ increase in the growth rate when the extracted casein was replaced by commercial casein or was supplemented with liver extracts. Zucker \& Zucker (1944) observed normal growth in rats if they increased the crude protein content of their diet from 20 to $27 \%$. Troescher-Elam \& Evans (I94I), on the other hand, noted no improvement in growth rate of mice if the level of extracted casein in a purified diet was increased. These findings indicate that it is impurities in commercial casein rather than the protein contribution of this foodstuff which promoted the improved growth rate. The body-weight increases observed by Hartman \& Cary (1942) were accompanied by increases in the weights of the ovaries, uterus and adrenals of females and of the seminal vesicles, prostate, epididymis and thymus of males. Similar increases were observed if whole liquid or dry skim milk was added to the diet.

It was noted in the present study that during lactation the mothers in all groups lost weight except those receiving the fresh-liver supplement or the stock diet. A similar observation has been made by Vinson \& Cerecedo (1943, 1944) and by Cerecedo $\&$ Vinson $(1944 b)$ in rats, and by Cerecedo \& Vinson (1944a) in mice. These authors found that, for both species, this loss of weight could be avoided, and normal lactation induced, by the addition of folic acid concentrates (Cerecedo \& Vinson, r $944 a, b$ ). The results of the fifth experiment (p. 46), in which the rats received folic acid, failed to confirm this observation for rats.

The reports from various laboratories on the use of purified diets in studies on growth, reproduction and lactation are not all strictly comparable, owing to variations in the intake of pure vitamins. It may be concluded, however, that, in order to produce normal performance in these respects, purified diets supplemented with the more readily available pure vitamins require further supplements. The essential factor or factors appear to be present in yeast, liver and commercial casein, while the work of Cerecedo \& Vinson (1944 $a, b)$ indicates that folic acid concentrates contain an essential factor. The present experiments showed that there was no improvement in reproduction and lactation when pure biotin and folic acid were added to a highly purified diet, but that the addition of a biotin concentrate caused a definite improvement in these respects. These results, together with those of other workers who used folic acid concentrates, suggest that some factor or factors in the concentrates other than biotin or folic acid are mainly responsible for this improvement.

Black \& Elvehjem (I94I) concluded that rats receiving purified diets can synthesize some of the essential B vitamins in their intestine, but that the rate of synthesis is not sufficiently rapid to maintain normal growth and lactation. The extent of intestinal synthesis depends, at any rate to some extent, on the relative and absolute intake of the members of the vitamin B group (cf. review by Kon, 1945). 


\section{SUMMARY}

I. Experiments were carried out in which growth, reproduction and lactation in rats were studied when the animals received a purified diet alone and also with various supplements. The diet consisted of extracted casein, sucrose, fat, salts and solutions of the following vitamins: $A, D, E, K, B_{1}, B_{6}$, riboflavin, calcium pantothenate, choline, nicotinic acid, inositol and $p$-aminobenzoic acid.

2. Five generations of rats were reared on the diet alone. Reproduction and lactation were subnormal and deteriorated with each succeeding generation. The growth rate of all animals was also subnormal.

3. The addition of cystine, arginine and histidine and of folic acid and biotin, in the pure form, caused no improvement in growth, reproduction and lactation.

4. Some improvement in lactational performance was noted after the addition to the diet of whole milk, a liver extract or a biotin concentrate. These additions only caused very slight improvements in reproduction as judged by the number of pups in a litter. The growth rate was also somewhat improved.

5. The addition of fresh liver resulted in approximately normal growth, reproduction and lactation.

6. It is concluded that for normal growth, reproduction and lactation the purified diet used, supplemented with the more readily available pure vitamins, requires further supplements, and that the factor (or factors) concerned is present in fresh liver, liver extracts, milk and a biotin concentrate.

Thanks are due to Dr T. H. Jukes, Lederle Laboratories, New York, for pantothenic acid and folic acid (through the courtesy of Prof. H. D. Kay); to Mr A. L. Bacharach, Glaxo Laboratories Ltd., for pantothenic acid and the liver extract; to S. M. A. Corporation, Chagrin Falls, Ohio, for the biotin concentrate (through the courtesy of Sir John Orr); to Dr T. F. Macrae for the pure biotin; to Dr R. E. Gruber, Merck and Co., Rahway, New Jersey, for vitamin $B_{6}$ at a time when it was not commercially available and to Dr J. H. Harrison, Roche Products Ltd., for the tocopheryl acetate.

\section{REFERENCES}

Black, S. \& Elvehjem, C. A. (194I). Bull. Wisc. agric. Exp. Sta. no. 453, p. 24.

Cerecedo, L. R. \& Vinson, L. J. (1944a). Arch. Biochem. 5, I 57.

Cerecedo, L. R. \& Vinson, L. J. (1944b). Arch. Biochem. 5, 469.

Cox, W. M. \& Imboden, M. (1936a). F. Nutrit. II, I47.

Cox, W. M. \& Imboden, M. (1936b). Proc. Soc. exp. Biol., N.Y., 34, 443.

Ershoff, B. H. (1943). Proc. Soc. exp. Biol., N.Y., 52, 41.

Folley, S. J., Henry, K. M. \& Kon, S. K. (1942). Nature, Lond., 150, 318.

Folley, S. J., Ikin, E. W., Kon, S. K. \& Watson, H. M. S. (1938). Biochem. Ұ. 32, 1988.

Foster, C., Jones, J. H., Dorfman, F. \& Kobler, R. S. (1943). F. Nutrit. 25, I61.

Hartman, A. M. \& Cary, C. A. (I942). J. Dairy Sci. 25, 679.

Henderson, L. M., McIntire, J. M., Waisman, H. A. \& Elvehjem, C. A. (r942). Э. Nutrit. $23,47$.

Jukes, T. H. (1940). Proc. Soc. exp. Biol., N.Y., 45, 625.

Kon, S. K. (1945). Proc. Nutrit. Soc. 3, 217.

Loureiro, A. de (1931). Arch. Patol., Lisboa, 3, 72.

Mackenzie, C. G., Mackenzie, J. B. \& McCollum, E. V. (194r). F. Nutrit. 21, 225.

Miller, E. C. \& Baumann, C. A. (1944). F. Nutrit. 27, 319.

Nakahara, W. \& Inukai, F. (1933). Sci. Pap. Inst. phys, chem. Res., Tokyo, 22, 301. 
Nakahara, W., Inukai, F. \& Kato, S. (1934). Sci. Pap. Inst. phys. chem. Res., Tokyo, 24, I55.

Nakahara, W., Inukai, F., Kato, S. \& Ugami, S. (1936). Sci. Pap. Inst. phys. chem. Res., Tokyo, $29,47$.

Nakahara, W., Inukai, F. \& Ugami, S. (1939). Sci. Pap. Inst. phys. chem. Res., Tokyo, 36, 327.

Nelson, M. M. \& Evans, H. M. (1945). Proc. Soc. exp. Biol., N.Y., 60, 319.

Richardson, L. R., Hogan, A. G., Long, B. \& Itschner, K. I. (1941). Proc. Soc. exp. Biol., N. Y., 46, 530.

Richardson, L. R., Long, B. \& Hogan, A. G. (1942). Amer. Chem. Soc. 1ozrd Mtg, p. B4.

Rogers, L. K., McElroy, L. W. \& Cowgill, G. R. (1942). Science, 95, 203.

Rombouts, J. E. \& Querido, A. (1946). Nature, Lond., 158, 792.

Sure, B. (r94r). F. Nutrit. 22, $49 \mathrm{r}$.

Troescher-Elam, E. \& Evans, H. M. (1941). Proc. Soc. exp. Biol., N.Y., 48, 549.

Vinson, L. J. \& Cerecedo, L. R. (1943). Fed. Proc. 2, 73.

Vinson, L. J. \& Cerecedo, L. R. (1944). Arch. Biochem. 3, 389.

Voris, L., Black, A., Swift, R. W. \& French, C. E. (1942). F. Nutrit. 23, 555.

Zucker, T. F. \& Zucker, L. (1944). Proc. Soc. exp. Biol., N.Y., 55, 136.

\title{
Formation of Fluorescent Pigment in Vitamin E Deficiency
}

\author{
By T. MOORE AND Y. L. WANG \\ Dunn Nutritional Laboratory, University of Cambridge and Medical Research Council
}

(Received 28 February 1947)

The brown discoloration of the uterus which occurs in rats deprived of vitamin $\mathrm{E}$ was first described by Martin \& Moore (1936). Later (1938) they reported that prolonged deficiency caused some degree of discoloration also in the skeletal muscles throughout the body, and particularly in the hind legs, which frequently became paralysed. The brown colour, therefore, appeared to be associated with the muscular dystrophy described by Ringsted (1935) and others, although there was some evidence that the process was not confined to muscular tissues. Thus, it was noticed that certain lymph nodes became decidedly brown. Histological examinations of the brown uterus revealed that the degenerated muscle cells were filled with small yellow granules (Barrie, 1938; Martin \& Moore, 1939). The phenomenon was studied further by Hessler (194I), Barrie Sweeten (1943), Demole (1941), Evans \& Emerson (1943), Oliveira (1946) and Faria (1946). In addition, Mason \& Emmel (1945) have recently made a detailed histological study which deserves special mention. In their opinion brown pigment is formed mainly, though not exclusively, in muscle cells, but is subsequently transferred to the tissue macrophages, and disseminated through the lymphatic system.

The purpose of the present paper is to report further experiments on the occurrence and on the chemical and physical characterization of the brown pigment, with particular reference to the fluorescent properties which have already been described in a preliminary communication (Moore \& Wang, 1943). Its characteristics will be compared with those of certain other brown pigments which have been reported by various workers to occur in the tissues of both experimental animals and human subjects. 